\title{
The Effect of Online Feedback Types on Foreign Language Writing*
}

\author{
Xiaoling Liu \\ College of Foreign languages, Hunan University, Changsha, P.R. China \\ Changping Zhou \\ Shandong Modern University, Jinan, Shandong, P.R. China
}

\begin{abstract}
In this study a comparison is made concerning the effect of online teacher feedback and online peer feedback on foreign language writing and the learners' attitudes toward online feedbacks. To address the issues, an experiment is carried out between two university classes, who received online teacher feedback and online teacher feedback respectively. Based on the analysis, the major findings are obtained as follows. Firstly, the writing in each group has been improved significantly after the application of online feedback. However, no significant difference is shown between groups A and B. Secondly, students in both groups can incorporate feedback into their revisions, though there exist some differences in the number of successful revisions and kinds of revisions between the two groups. Finally, both online teacher feedback and online peer feedback are very well received by most students respectively. The research findings indicate that online feedback should be adopted in foreign language writing teaching.
\end{abstract}

Index Terms - foreign language writing, revision writing, online teacher peer feedback, online peer feedback

\section{INTRODUCTION}

Writing is seen as an important skill for foreign language learners. In foreign language learning, writing can not only improve grammatical learning and vocabulary, but be conductive to express the writer's ideas and develop the awareness of language.

In process writing theory, feedback has been regarded as an important part of foreign language writing, and has gained increasing attention in ESL. Many studies on feedback have been conducted (Keh, 1990; Hyland, 2003; Yang et al, 2006). Some research tries to discover the nature and function of feedback (Ferris \& Roberts, 2001; Hyland, 2003). Other research discusses the effect of written teacher feedback and written peer feedback on writing (Yang et al, 2006; Lee, 2007). In Paulus's study (1999), the author indicates both peer and teacher feedback contributed to the revision process, with the teacher feedback bringing about more revision and favored more by students and required revision could significantly raise the essay scores of the class. Tsui and Ng's (2000) study of Hong Kong secondary schools and Hu's (2005) study of Chinese students studying English in Singapore also showed positive attitude toward peer feedback.

In recent years, with the development of information technology, especially, the wide use of Internet, the combination of Internet and language teaching and learning becomes a tendency. Therefore, some studies on online feedback are conducted, focusing mainly on the effect of online peer feedback on the writings of foreign language learners (Yang \& Meng, 2013), and the effect of online peer feedback compared with traditional peer feedback on second or foreign language writing (Tuzi, 2004; Liu \& Sadler (2003). However, scanty research into different types of online feedback on foreign language writing has been done. Therefore, a study is necessary to investigate the effect of online feedback types on foreign language writing and to explore foreign language learners' perception of online feedback types.

\section{LITERATURE REVIEW}

\section{A. Collaborative Learning}

Collaborative learning is a process in which students work together with peers or teachers to solve problems, so that they can actively construct knowledge, rather than passively accept knowledge from teachers or the textbook. Rebecca, L (1997, p.443) refers to collaborative learning as "construction of knowledge within a social context and encouraging acculturation of individuals into a learning community." Panitz (1999, p.5) also thinks that collaborative learning is "a set of processes which help people interact together in order to accomplish a specific goal or develop an end product which is usually content specific." In the process, students can actively participate in the community, communicate or discuss with their members in the group, and then share information to accomplish the specific goal.

\footnotetext{
${ }^{*}$ Funded by Hunan social science program (12YBA072)
} 
Collaborative learning is also a learning strategy, which, according to Liu \& Liu (2009), means students and teachers find solutions to problems through interaction in order to achieve the same teaching and learning goals. Quite different from the traditional teacher-centered approach, collaborative learning is student-centered. Namely, students are responsible for their own learning, while teachers only play roles such as facilitators or guides, who just observe and provide some suggestions whenever necessary.

With its wide use in language teaching and learning, Internet provides a good environment for facilitating collaborative learning. With no restraint of time and space, students can have more chances to communicate, and discuss with their teachers or peers through E-mail, QQ, or other online tools, so that they can pool their ideas, solve problems and then learn from each other (Li et al., 2008).

\section{B. Process Approach Theory}

Process approach has greatly influenced foreign language writing research and teaching. However, there is not a definite definition for the term. Keh (1990, p.294) refers to process approach as "multiple-draft process which consists of: generating ideas (pre-writing); writing a first draft with an emphasis on content (to 'discover' meaning/author's ideas); second and third (and possibly more) drafts to revise ideas and the communication of those ideas." Thus process approach is often defined as the creative act of writing which requires time and feedback to be done.

Flower and Hayes (1981) describe writing as a recursive process, in which the writer plans, translates ideas into language, and reviews what has been written. Goldstein \& Carr (1996) state that process writing refers to various strategies that include pre-writing activities, planning and then writing, as well as drafting and revising. Badger \& White (2000) suggest that process approach stresses linguistic skills, like planning and drafting rather than linguistic knowledge such as grammar and text structure knowledge. Thus it can be seen that process approach focuses on the writing itself, and is a non-linear, recursive process, in which students participate actively in every stage, and discover or construct knowledge. In the process, writing not only refers to the output of linguistic knowledge such as grammar and syntax, but means what to write, and how to write.

Process approach emphasizes the whole process of writing, including pre-writing, drafting, feedback and revising, and rewriting (Mckensie \& Tomkins, 2010). Pre-writing is the preparation stage, in which students should know the purpose and audience of the writing, and then determine their topics, collect relevant materials and develop their ideas following the specific techniques such as brainstorming, questioning and outlining. Subsequently students start to work out their drafts. During the stage students make use of the result of pre-writing to create their own writing and develop the content of the writing. Feedback and revising stage plays a significant role in the process approach, during which feedback is provided by teachers or peers, and then students revise their draft in terms of linguistic knowledge, topic, content as well as structure. Thus, revision can improve the students' writing ability and also the readability of the writing. The last step is to rewrite. Students rewrite their passage based on the feedback and revision. The study focuses on the last three steps: drafting, feedback and revising, and rewriting stage, with feedback playing a central role in writing, connecting drafting with revising.

\section{Definition of Feedback}

Feedback is an important element in the process approach. Tsui \& $\mathrm{Ng}$ (2000, p.148) stresses the importance of feedback as a "central and critical contribution to the evolution of a piece of writing. Feedback informs the writing process, permeating, shaping, and molding it." As defined by Keh (1990, p.294-295), feedback is "an input from a reader to a writer with the effect of providing information to the writer for revision." and "through feedback, the writer learns where he or she has misled or confused the reader by not supplying enough information, illogical organization, lack of development of ideas, or something like inappropriate word-choice or tense." Following the scholars, in this study feedback means suggestions or some concrete revising information which can provide clues to better writing.

\section{Feedback in Writing}

Feedback can be categorized into teacher feedback and peer feedback, following the criterion of who provides it. Teacher feedback on student writing has been widely explored in the foreign language classroom. Some look into the form and content of the teacher feedback. For example, Hyland (2003) indicated that though teacher feedback focusing on form could have immediate impact on the revision to their drafts, it had no significant influence in writing development. Montgomery \& Baker (2007) pointed out that teachers gave more feedback on local issues such as grammar and spelling than on global issues such as idea and content.

Some explore the effect of the teacher feedback on students' writing. Ferris \& Roberts (2001) found that students who received error feedback from teachers performed better in content than those who received no feedback.

Others investigate students' perception and attitudes toward teacher feedback. Straub (1997) found that students had equal interest in receiving teacher feedback on global issues such as content and purpose, and on local matters of word and grammar. Tsui \& Ng (2000) confirmed that most students favored teacher comments than peer comments, and teacher comments could lead to more revisions.

Peer feedback has also been a hot issue. Some explore the benefits of peer feedback on students' writing (Keh, 1990; Lochhart \& Ng, 1993). They pointed out that peer feedback can save teachers' time, raise the audience awareness, and also help students improve their writing by reading writings of peers. However, some scholars (Zhang, 1995; Nelson 
and Carson, 1998) question the advantages of peer feedback. They revealed that ESL writers preferred teacher feedback to peer feedback based on the affective values of feedback and that they made use of more teacher comments than peer comments in their revisions.

Others have compared the effectiveness of teacher feedback and peer feedback on revision writing. Based on Yang's study (2006), students could make good use of both teacher and peer feedback, with the difference lying in the fact that teacher feedback could lead to more surface revision such as vocabulary and grammar, while peer feedback more meaning revision. They also found that $90 \%$ of teacher feedback was incorporated in students' revisions against $67 \%$ of peer feedback. By contrast, Lee (2007) pointed that students could not utilize teacher feedback fully because students saw teacher feedback as indication of written errors.

It can be seen that scholars hold mixed views in terms of the effectiveness of teacher feedback and peer feedback.

\section{E. Online Feedback in Writing}

With the integration of Internet and language teaching and learning, more attention is put on online feedback. Compared with traditional studies on teacher feedback, the studies concerning online teacher feedback on students' writing are relatively less. Some focus on the students' attitude toward online teacher feedback. For instance, Duan (2011) investigated the acceptance and student's likings for types of online teacher feedback and found that one-to-one online feedback like e-mail is very popular with students, and feedback like suggestions is liable to be accepted by students.

Others investigate the effect of online teacher feedback on revision (Yang et al. 2013; Alvarez et al. 2012). For example, Alvarez et al. (2012) suggested that through the exploration of the nature and function of online teacher feedback on the students' text revisions, students could make use of online teacher feedback positively and improved their writings constructively, especially when the feedback took on forms of suggestions and questions rather than direct correction. All in all, specific studies on online teacher feedback are rather rare.

In the case of research on online peer feedback, some research mainly focused on the advantages of online peer feedback. Tuzi (2004) showed online peer feedback has the advantages of not being restrained by time or place, can thus increase the amount of student participation, improve the ability to monitor conversations and reduce the role of the teacher. According to Jiang (2005), based on the comparison of online peer revision with face-to-face peer revision, online peer feedback was powerful in enhancing learners' stimulus and motivation in writing, reducing anxiety and stress, and also revising the passage as a whole. Chen (2008) confirmed Jiang's findings later on. The explanation is that students in the Internet environment can feel more relaxed and have less pressure, and thus are willing to express their points of view and suggestions on peers' writing. Sullvan \& Pratt (1996) found students in the computer-assisted classroom showed more interest in peer discussion compared to only 50\% participation in the face-to-face class, and then led to more practice in writing. However, as Liu \& Hansen (cited in Martin \& Shi, 2007) pointed out, these advantages can be constrained by students' level of English proficiency, which affects the quantity, quality and comprehension of peer feedback, and also by students' cultural backgrounds, which affect their classroom behaviors and the amount of participation.

Some studies make investigation into the effect of online peer feedback on the second or foreign language writing (Birch, 2016; Liu \& Sadler, 2003; Moradi, 2012). For instance, Liu \& Sadler (2003) indicated that electronic peer review could produce more overall comments and a larger percentage of revision-oriented comments with the focus on local revision. However, Jones et al.'s (2006) and Yang's (2010) findings are different from that of Liu \& Sadler (2003), they discovered that students in a first year writing class were more likely to discuss textual issues such as grammar and vocabulary in face-to-face sessions, but tended to focus on global revisions such as content, organization and topic in synchronous online sessions. Tannacito \& Tuzi (2002) in their study concluded that electronic peer feedback had made influential changes in revisions in larger blocks of text and in adding new content to the essay. Furthermore, Tuzi (2004) explored the relationship between peer and teacher electronic feedback and their impact on second language writers' revision, and found that electronic feedback had a great impact on revision than oral feedback, and second language writers used e-feedback to create more macro-level revisions at the clause, sentence, and paragraph levels, with new information added. However, there was no clear indication that the impact made by peer electronic feedback was greater than that of teacher electronic feedback. Moradi (2012) studied 60 EFL students' experience of online peer feedback in essay writing, and revealed that there existed no significant difference in the performance of the online and offline groups.

In addition, there are some studies that explore the perception of students to the online peer feedback. Some research find positive attitude toward online peer feedback. DiGiovanni \& Nagaswami (2001) and Chen et al (2011) indicated that students had preference for online peer feedback and most of them were willing to receive online peer feedback. By contrast, there was some other research which showed mixed attitudes toward online peer feedback. For example, Tuzi (2004) discovers that although electronic feedback had a great impact on revision than oral feedback, students prefer to oral feedback. Martin \& Shi (2007) reveal that students had mixed feeling in terms of the liking and disliking for online peer feedback. Similar result is also obtained in Jane et al.'s study (2008), in which most students preferred the online peer feedback in the questionnaire, but there were still many students who enjoyed face-to-face interaction. What is more, In Ge's study (2011), all participants held positive attitudes to the online peer feedback with the focus on the 
grammar and vocabulary, but they still wanted to get the teacher's view. To some extent, the attitude of students to the online peer feedback is similar to that of traditional peer feedback.

As mentioned in the literature above, research regarding both traditional feedback and online feedback has confirmed that feedback plays an important role in writing. However, research on the comparison of effectiveness of different online feedback types on foreign language writing is scanty. Therefore, it is imperative to conduct a study to compare the effect of online peer feedback with that of online teacher feedback.

\section{RESEARCH DESIGN}

\section{A. Research Questions}

To investigate the effect of online feedback on foreign language writing, the study mainly addressed the following research questions:

1. To what extent do online teacher feedback and online peer feedback affect foreign language learners' writing respectively?

2. How do online teacher feedback and online peer feedback affect the learners' revision writing?

3. What are foreign language learners' attitudes toward online teacher feedback and online peer feedback in writing?

\section{B. Participants}

Fifty-five participants from two sophomore classes are chosen: Engineering Management class (Group A) and Building Energy class (Group B) in a famous university in China. The pretest scores showed that two groups are homogeneous in terms of writing proficiency. Thus it is determined that Group A receive online teacher feedback, and Group B receive online peer feedback treatment. In addition, all the participants have passed CET-6, so they are able to provide peer feedback with high quality.

\section{Instruments}

The instruments used in the study mainly included four writing tasks, pre-test and post test writing, two questionnaires and the SPSS.

Students in the two groups were required to finish four different argumentative writing tasks in the study, with the first two for treatment and the last two writing task data collected and analyzed to investigate how online teacher feedback and online peer feedback affected the students' revision in their writing.

The pretest writing was used to investigate whether students' writing ability in both groups had a significant difference before the experiment, while the posttest writing was used to investigate whether students' writing ability in both groups would improve and whether there was a significant difference in writing between both groups after the treatment of online teacher feedback and online peer feedback respectively.

Two questionnaires were mainly used to investigate student's attitudes toward online teacher feedback and online peer feedback respectively.

Finally, the data collected were analyzed by SPSS to help analyze the effects of online teacher feedback and online peer feedback on students' writing in general and revision writing in particular.

\section{Materials}

The materials included writing tasks for treatment and testing, rating rubric and two questionnaires.

The topics for the four writing tasks, pretest and posttest writings are chosen from CET-6 in order to guarantee the reliability of the study.

TABLE 1.

WRITING MATERIALS

\begin{tabular}{|l|l|}
\hline Writing materials & Topics \\
\hline Four writing training tasks & How to Improve Student's Mental Health \\
\cline { 2 - 2 } & How I Finance My College Education \\
\cline { 2 - 2 } & My View on Job-Hopping \\
\cline { 2 - 2 } & Reading Selectively or Extensively \\
\hline Pretest & Should Firecrackers be Banned \\
\hline Posttest & Is a Test of Spoken English Necessary \\
\hline
\end{tabular}

The rubric for CET-6 is adopted to rate writing,. The essays were scored from content, language expression, discourse coherence and structure. Both pretest and posttest writing were scored by two raters, the rating inter-reliability of whom was 0.95 as shown by SPSS analysis.

The two questionnaires were modified following Xiang (2010) to guarantee the reliability. His questionnaires were designed to investigate student's attitudes toward teacher and peer feedback in college English writing. The two questionnaires were modified, including 17 items in questionnaire one for online teacher feedback group, and 19 items in questionnaire two for online peer feedback group. The questionnaires were presented in Chinese, so that students could understand better. Both consisted of two parts, with part 1 involving the basic information about the participants, and part 2 specific items in terms of overall attitude, content, as well as the response of students to online teacher 
feedback and online peer feedback respectively. All the students are required to rate the acceptability of each item on a 5-point Likert scale.

\section{E. Procedures}

All the participants took a writing test on April 22, 2016 to make sure they are homogeneous in writing.

Following the pretest was the treatment, which started in May, 2016 and lasted for 6 weeks. Both groups finished four writing tasks, and they were required to write twice for each topic, following the steps below: (1) the first draft, (2) online teacher feedback or online peer feedback, (3) the second draft. The first two writing tasks were designed to familiarize the participants with online feedback, especially for online peer feedback group. The last two writing tasks were completed separately by both groups. Besides, students in Group B were divided into pairs so that each had a peer to read their writing and offer online peer feedback. When the first drafts were finished, they were sent to their peers or teacher by E-mail for feedback, and then they rewrote their essays according to feedback provided by their peers or teacher.

After the treatment, two questionnaires were handed out to the students in both groups, and they were required to finish them in ten minutes in class. Finally, all participants were supposed to take a post-test writing within 30 minutes, to figure out whether there was any effect of online feedback in writing and whether there existed any effect differences between the two online feedback types.

\section{F. Data Collection and Data Analysis}

Data collected in the experiment include pretest scores, the third and fourth writing task data, posttest score, and data of two questionnaires.

Firstly, paired-sample t-test was adopted to see whether online feedback had any effect on students' writing in general and independent-sample t-test to find whether there was any significant difference between two online feedback groups in particular.

Secondly, the third and fourth writing task data, including the first drafts, online teacher feedback or online peer feedback, and revision drafts, were analyzed from two perspectives: the usable feedback provided by the teacher or peers following Hyland's definition (1998), and successful revisions following Conrad and Goldstein's (1999) classification, and kinds of revisions according to Faigley and Witte's taxonomy (1981). In addition, to ensure the reliability, another teacher was invited to do the analysis, with the agreement rate reaching $92 \%$.

Finally, questionnaire data were analyzed from three dimensions: overall attitude, contents, and students' response to both online teacher feedback and online peer feedback. For the choices of the answers, different values were assigned: 5 for "Strongly agree", 4 for "Agree", 3 for "Not sure", 2 for "Disagree" and 1 for "Strongly disagree".

\section{RESULT AND DISCUSSION}

\section{A. Online Feedback Effect on Writing}

In order to investigate the extent to which online teacher feedback and online peer feedback affect foreign language learners' writing respectively, both paired sample t-test and independent sample t-test were presented as shown in table 2 , and table 3 .

TABLE 2.

PAIRED SAMPLE T-TEST FOR BOTH GROUPS

\begin{tabular}{l|l|l|l|l|l}
\hline \multicolumn{2}{c}{} & & & PAIRED SAMPLE T-TEST FOR BOTH GROUPS \\
\multicolumn{2}{c|}{} & Mean & N & Std. Deviation & $\begin{array}{l}\text { Std. Error } \\
\text { Mean }\end{array}$ \\
\hline \multirow{3}{*}{ GA } & Pretest & 9.6154 & 26 & 1.76809 & .34675 \\
\cline { 2 - 6 } & Posttest & 11.2308 & 26 & 1.33589 & .26199 \\
\hline \multirow{3}{*}{ GB } & Pretest & 9.6552 & 29 & 1.75816 & .32648 \\
\cline { 2 - 6 } & Posttest & 10.8621 & 29 & 1.78734 & .33190 \\
\cline { 2 - 6 } & & & &
\end{tabular}

\begin{tabular}{|c|c|c|c|c|c|c|c|c|c|}
\hline & & \multicolumn{5}{|c|}{ Paired Differences } & \multirow[b]{3}{*}{$\mathrm{T}$} & \multirow[b]{3}{*}{ Df } & \multirow[b]{3}{*}{ Sig. (2-tailed) } \\
\hline & & \multirow[b]{2}{*}{ Mean } & \multirow[b]{2}{*}{ Std. Deviation } & \multirow{2}{*}{$\begin{array}{l}\text { Std. Error } \\
\text { Mean }\end{array}$} & \multicolumn{2}{|c|}{$\begin{array}{l}\text { 95\% Confidence Interval of } \\
\text { the Difference }\end{array}$} & & & \\
\hline & & & & & Lower & Upper & & & \\
\hline GA & $\begin{array}{l}\text { pretest - } \\
\text { posttest }\end{array}$ & -1.61538 & 1.41639 & .27778 & -2.18748 & -1.04329 & -5.815 & 25 & .000 \\
\hline GB & $\begin{array}{l}\text { pretest - } \\
\text { posttest }\end{array}$ & -1.20690 & 1.78044 & .33062 & -1.88414 & -.52966 & -3.650 & 28 & .001 \\
\hline
\end{tabular}

The mean scores of both groups in pretest and posttest indicate students' writing has been improved to some extent. And the sig values of 0.000 and 0.001 in the paired sample t-tests suggest a statistically significant difference after the online feedback treatment for both groups. 
Although as presented above, both online feedback groups improved statistically significant in writing, it is not clear whether there is any significant difference between the two different online feedback groups? Therefore, independent-sample t-test is used to reveal the results.

TABLE 3.

COMPARISON OF TWO ONLINE FEEDBACK TYPES ON WRITING

\begin{tabular}{|c|c|c|c|c|c|}
\hline \multicolumn{2}{|l|}{ Group } & \multirow{2}{*}{$\frac{\mathrm{N}}{26}$} & \multirow{2}{*}{$\begin{array}{l}\text { Mean } \\
11.2308\end{array}$} & \multirow{2}{*}{$\frac{\text { Std. Deviation }}{1.33589}$} & \multirow{2}{*}{$\begin{array}{l}\text { Std. Error Mean } \\
.26199\end{array}$} \\
\hline Posttest & group A & & & & \\
\hline & Group B & 29 & 10.8621 & 1.78734 & .33190 \\
\hline
\end{tabular}

\begin{tabular}{|c|c|c|c|c|c|c|c|c|c|c|}
\hline & & \multicolumn{2}{|c|}{$\begin{array}{l}\text { Levene's Test for } \\
\text { Equality of } \\
\text { Variances }\end{array}$} & \multicolumn{7}{|c|}{ t-test for Equality of Means } \\
\hline & & \multirow[b]{2}{*}{$F$} & \multirow[b]{2}{*}{ Sig. } & \multirow[b]{2}{*}{$\mathrm{T}$} & \multirow[b]{2}{*}{ Df } & \multirow{2}{*}{$\begin{array}{l}\text { Sig. } \\
\text { (2-tailed) }\end{array}$} & \multirow{2}{*}{$\begin{array}{l}\text { Mean } \\
\text { Difference }\end{array}$} & \multirow{2}{*}{$\begin{array}{l}\text { Std. Error } \\
\text { Difference }\end{array}$} & \multicolumn{2}{|c|}{$\begin{array}{l}\text { 95\% Confidence Interval of } \\
\text { the Difference }\end{array}$} \\
\hline & & & & & & & & & Lower & Upper \\
\hline \multirow[t]{2}{*}{ posttest } & $\begin{array}{l}\text { Equal } \\
\text { variances } \\
\text { assumed }\end{array}$ & 5.426 & .024 & .858 & 53 & .395 & .36870 & .42955 & -.49287 & 1.23027 \\
\hline & $\begin{array}{l}\text { Equal } \\
\text { variances } \\
\text { not assumed }\end{array}$ & & & .872 & 51.410 & .387 & .36870 & .42284 & -.48003 & 1.21743 \\
\hline
\end{tabular}

As it can be seen in table 3, the mean scores for Group A and Group B are 11.2308 and 10.8621 respectively, which is rather close to each other. And the sig value is 0.395 , higher than the significance level 0.05 , showing no significant difference of student's writing ability after receiving two different online feedback types. To sum up, both online teacher feedback and online peer feedback have statistically significant effect on students' writing. However, there exists no significant difference between the two different online feedback type groups.

\section{B. Online Feedback Effect on Revision Writing}

The drafts of the third and fourth task written by both groups were collected and analyzed in order to address how online teacher feedback and online peer feedback affect students' revision writing. And the drafts were analyzed in terms of usable feedback provided by the teacher or peers, successful revisions and kinds of revisions influenced by feedback.

a. Feedback Points Used in Revision

To determine how many feedback points were used in their revisions, Hyland's (1998) definition was adopted: feedback points as each written intervention focusing on a different aspect of the text, and consisted of symbols and marks in the margins, underling of problems, complete correction, as well as more detailed comments and suggestions. In addition, Hyland (1998) defined useable feedback as the potential for revision of draft. For example, the teacher's comment on the wrong word "different" was regarded as usable feedback, while the teacher's comment like "Good job" was considered unusable feedback. The number of usable feedback points and that used by the students in their revision writing were shown in the following table.

TABLE 4.

PERCENTAGE OF FEEDBACK USED IN REVISION

\begin{tabular}{l|l|l}
\hline Groups & usable feedback points & used feedback points \\
\hline Group A & 265 & $253(95.4 \%)$ \\
\hline Group B & 414 & $350(84.5 \%)$ \\
\hline
\end{tabular}

As is shown in table 4, Group A received in total 265 usable feedback points, with 253 incorporated in their revision, reaching $95.4 \%$, while Group B incorporated 350 out of 414 usable feedback points.

It can be found students in Group B ignored more feedback points, which is perhaps due to the difference in language proficiency between the teacher and students. Comparatively, the teacher can provide more comprehensive and accurate feedback. What's more, students believe in their teacher more, and think that the teacher is more professional and trustworthy than their peers.

b. Successful Revisions Made

Then how do the online feedback types affect the students' revision. To find out the issue, Conrad and Goldstein's (1999, p.154) classification of revision is followed: successful revision, unsuccessful revision, and no change. "Successful revision" were defined as "those solving a problem or improving upon a problem area discussed in the feedback", "unsuccessful revision" were defined as "those that did not improve the text or that actually further weakened the text". "No change" was defined as "feedback points not acted on and so were excluded in the coding". In addition, there were some revisions that could not be traced to online teacher feedback or online peer feedback, so it could be regarded as self revision. 
TABLE 5.

IMPACT OF ONLINE FEEDBACK ON SUCCESSFUL REVISIONS

\begin{tabular}{l|l|l|l|l}
\hline \multirow{2}{*}{ Groups } & Revisions & Unsuccessful & No changes & Self- revision \\
\cline { 2 - 5 } & Successful & 18 & 12 & 8 \\
\hline Group A & $235(92.8 \%)$ & 64 & 64 & 2 \\
\hline Group B & $286(81.7 \%)$ & 64 & \\
\hline
\end{tabular}

It can be seen from table 5, there exists some difference in the effect of online feedback on students' revision in their writings. Firstly, Group A make 235 successful revisions out of 253 used feedback points, while Group B 286 out of 350, with Group A making 11.1\% more successful revisions. The potential explanation is that the teacher has corrected most mistakes directly, so students in Group A can directly incorporate them in their writing. However, most peers in Group B just underline the mistakes. Secondly, in terms of unsuccessful revisions made, Group A make 18 out of 253 used feedback points, while Group B 64 out of 350. It can be found that there are occasions students in both groups failed to understand the feedback provided. Thirdly, Group A have 12 feedback points ignored, compared with 64 for Group B. It can be explained that students occasionally doubt their peer's ability to provide professional and trustworthy feedback. In addition, online feedback has also brought about some self revisions, which indicates that students in both groups have autonomous learning ability when they revise their drafts. Students don't depend on their teacher or peers completely, and they have their own judgments.

c. Kinds of Revision Made

Faigley and Witte's (1981) taxonomy was used as the framework to analyze the kinds of revision brought about online feedback. Revision can be classified into surface changes that do not bring new information to text and meaning changes that add or delete some information to content of the writing.

TABLE 6.

IMPACT OF ONLINE FEEDBACK ON KINDS OF REVISION

\begin{tabular}{l|l|l}
\hline Groups & Surface changes & Meaning changes \\
\hline Group A & $211(80.8 \%)$ & 50 \\
\hline Group B & $313(88.9 \%)$ & 39 \\
\hline
\end{tabular}

Table 6 shows that among the revision kinds made, Group A make 211 surface changes and 50 meaning changes, while Group B 313 surface changes and 39 meaning changes. Although Group B make more surface changes than Group A, they provide less meaning changes. It can be explained that the teacher in Group A has the ability to provide more feedback concerning ideas, and structure of students' writing, while peers in Group B provide feedback mainly concerning mistakes in grammar and vocabulary.

To conclude, online feedback does make some difference in students' revision writing. Both the teacher and the peers provide usable feedback online, which lead to some difference in both successful revisions and kinds of revisions.

\section{Attitude toward Online Feedback}

In order to investigate students' attitudes towards online feedback, two questionnaires are handed out to the two groups of students respectively. Students' attitudes are presented following three dimensions: overall attitude, contents, and responses to online feedback as shown in table 7 and table 8.

TABLE 7.

ATTITUDE TOWARD ONLINE TEACHER FEEDBACK

\begin{tabular}{|c|c|c|c|c|c|}
\hline \multirow[t]{2}{*}{ Dimensions } & \multicolumn{5}{|c|}{ Percentage of opinion $(\%)$} \\
\hline & 5 & 4 & 3 & 2 & 1 \\
\hline Overall attitude & 73.1 & 26.0 & 0.9 & 0 & 0 \\
\hline contents & 50.5 & 30.0 & 17.0 & 2.7 & 0 \\
\hline Responses to online teacher feedback & 85.3 & 12.8 & 1.9 & 0 & 0 \\
\hline
\end{tabular}

Generally speaking, up to $99 \%$ of students prefer online teacher feedback. With regard to the attitudes towards the contents, $80.5 \%$ of students think online teacher feedback not only concerns grammar, vocabulary, but also idea, and structure of their writing. As to how students respond with online teacher feedback, again the majority of students express strong agreement that they would read their teacher feedback carefully, and then revise their writings accordingly. This can explain why students in Group A can improve a lot in their writing. It can be summarized that students' attitude toward online teacher feedback is positive. Table 8 below will present the results of students' attitude to online peer feedback. 
TABLE 8.

ATTITUDE TOWARD ONLINE PEER FEEDBACK

\begin{tabular}{|c|c|c|c|c|c|}
\hline \multirow[t]{2}{*}{ Aspects } & \multicolumn{5}{|c|}{ Percentage of opinion (\%) } \\
\hline & 5 & 4 & 3 & 2 & 1 \\
\hline Overall attitude & 17.9 & 53.8 & 14.5 & 13.8 & 0 \\
\hline contents & 8.4 & 41.4 & 22.2 & 25.1 & 3.0 \\
\hline Responses to online peer feedback & 37.4 & 53.2 & 8.4 & 1.0 & 0 \\
\hline
\end{tabular}

The overall attitude is positive, with $71.7 \%$ of students showing their preference for online peer feedback. As for the contents, the responses are mixed, with most students considering online peer feedback paying too much attention to language itself, and some logistics while ignoring ideas, structure etc. With regard to reactions to online peer feedback, the majority of students hold that they can read their peer feedback carefully, and then revise their writings according to the feedback, which perhaps explains why students in Group B also make great improvements in their writing. It can thus be seen clearly that students' attitude toward online peer feedback is also positive.

\section{CONCLUSION}

Based on the results and discussion above, some major findings concerning the three research questions can be obtained, and some pedagogical implications can be suggested.

\section{A. Major Findings}

Firstly, both online teacher feedback and online peer feedback can play a positive role in foreign language writing. Students in both groups have made much progress after the treatment of online teacher feedback or online peer feedback respectively. However, there exists no significant difference between Group A and Group B .

Secondly, both online teacher feedback and online peer feedback have effect on students' revision in writing. Students can read the feedback points carefully, and incorporate them into their revision writing, leading to successful revisions and different kinds of revisions.

Finally, students' attitude toward both online teacher feedback and peer feedback is positive in general. Most students hold they benefit a lot from online feedback.

\section{B. Pedagogical Implications}

Firstly, the integration of technology into FOREIGN LANGUAGE classroom is not only possible but also advantageous, for it can get accessed without the restraint of time and space. For example in terms of writing teaching or learning, it can provide a good platform where students can have more communication, discussion with their teachers or peers through E-mail, QQ, or other online tools to pool their ideas, and solve problems.

Secondly, teachers are encouraged to provide more online feedback, for feedback is an important part in the process-oriented writing, which can help improve students' writing not only in terms of language, but also ideas, structure etc. Students then should follow online teacher feedback and make revisions, thus improving their writing.

Thirdly, students should be encouraged to provide online peer feedback, for this goes good not only to others, but also to their own learning process as well. By reading other peers' writing, they can learn a lot and thus improve their own writing. Besides, the process can help students construct language knowledge actively, and develop collaborative learning as well.

To sum up, both online teacher feedback and online peer feedback should be adopted in writing teaching. They can be integrated to improve students' writing ability, and get students participate actively in the revision process.

\section{REFERENCES}

[1] Alvarez, I., Espasa, A. \& Guasch, T. (2012). The value of feedback in improving collaborative writing assignments in an online learning environment. Studies in Higher Education, 37(4), 387-400.

[2] Badger, R. \& White, B. (2000). A process genre approach to teaching writing. ELT Journal, 54(2), 153-160.

[3] Birch, Heath er J.S. (2016). Feedback in online writing forums: Effects on adolescent writers. Teaching/Writing: The Journal of Writing Teacher Education, 5(1), 74-89.

[4] Chen, C., Leung, K. \& Maxwell, G. (2011). Peer assessment using Wiki to enhance their mastery of the Chinese language. Retrieved from: http://www.doc88.com/p-7088647052867.html. 16 July 2017.

[5] Chen, Suqin. (2008). QQ group chatting and English writing online peer feedback. Journal of Chengdu University (Educational Sciences Edition) 22(10), 62-64.

[6] Deng et al. (2003). A systematic study of process approach and its implications for the teaching reforms of college English writing. Foreign language Education 24(6), 58-62.

[7] DiGiovanni, E. \& Nagaswami, G. (2001). Online peer review: An alternative to face-to-face? ELT Journal 55, $263-272$.

[8] Duan, Aohui. (2011). A Survey of Effects of Teacher Feedback to English Autonomous Learning of College Students under Network Environment. Journal of Xuzhou Normal University (Educational Science Edition), 2(2), 45-48.

[9] Faigley, L. \& Witte, S. (1981). Analyzing Revision. College Composition and Communication, 32 (4), $400-414$.

[10] Ferris, D. R., \& Roberts, B. (2001). Error feedback in L2 writing classes: how explicit does it need to be? Journal of Second Language Writing, 10, 161-184. 
[11] Flower, L. \& Hayes, J. R. (1981). A cognitive process theory of writing. College Composition and Communication, 32 (4), 365-387.

[12] Ge, Zigang. (2011). Exploring e-learners' perceptions of net-based peer-reviewed English writings. Computer-supported Collaborative Learning, 6, 75-91

[13] Hu, Guangwei. (2005). Using peer review with Chinese ESL student writers. Language Teaching Research, 9(3), 321-342.

[14] Hyland, F. (2003). Focusing on form: student engagement with teacher feedback. System, 31, 217-230.

[15] Jane, G., Alan, D \& Anne, R. (2008). Peer interaction and critical thinking: Face-to-face or online discussion? Learning and Instruction, 18, 187-200.

[16] Jiang, Yuhong. (2005). The Role of online peer review in learners' writing ability development. Foreign language Teaching and Research (bimonthly), 37(3), 226-230.

[17] Keh, C. L. (1990). Feedback in the writing process: a model and methods for implementation. ELT Journal, 44, $294-304$.

[18] Lee, I. (2007). Feedback in Hong Kong secondary writing classrooms: Assessment for learning or assessment of learning? Assessing Writing, 12, 180-198.

[19] Li, Q., Lau, R. W. H., Shih, T. K., and Li, F. W. B. (2008). Technology supports for distributed and collaborative learning over the Internet. ACM Transactions on Internet Technology, 8(2), 1-24

[20] Liu, J. \& Sadler, R. W. (2003). The effect and affect of peer review in electronic versus traditional modes on L2 writing. Journal of English for Academic Purposes, 2, 193-227.

[21] Lockhart, C. \& Ng, P. (1993). How useful is peer response? Perspectives, 5(1), 17-29.

[22] Martin, G \& Shi, L. (2007). ESL students' experiences of online peer feedback. Computers and Composition, $24,443-461$.

[23] Montgomery, J. L. \& Baker, W. (2007). Teacher-written feedback: Student perceptions, teacher self-assessment, and actual teacher performance. Journal of Second Language Writing, 16, 82-99.

[24] Moradi, M. R. (2012). The effect of online peer feedback on the academic writing ability of Iranian EFL learners. International Education Studies, 5(2), 11-117.

[25] Panitz, T. (1999). Collaborative versus cooperative learning: A comparison of the two concepts which will help us understand the underlying nature of interactive learning. Retrieved from: https://www.researchgate.net/publication/311497094. 16 July 2017.

[26] Straub, R. (1997). Students' reactions to teacher comments: an exploratory study. Research in the Teaching of English 31, 91-119.

[27] Sullivan, N. \& Pratt, E. (1996). A comparative study of two ESL writing environments: A computer-assisted classroom and a traditional oral classroom. System 24, 491-501.

[28] Tsui, A.B.M. \& Ng. M. (2000). Do secondary L2 writers benefit from peer comments? Journal of Second Language Writing 9 (2), 147-170.

[29] Tuzi, F. (2004). The impact of e-feedback on the revisions of L2 writers in an academic writing course. Computers and Composition 21, 217-235.

[30] Yang, Miao. (2006). A comparative study in the Chinese EFL writing class. Modern Foreign languages (Quarterly) 29(3), 293-301.

[31] Yang, M., Badger, R. \& Yu Zhen. (2006). A comparative study of peer and teacher feedback in a Chinese EFL writing class. Journal of Second Language Writing 15, 179-200.

[32] Yang, Y., \& Meng, W. (2013). The effects of online feedback training on students' text revision. Language Learning \& Technology, 17 (2), 220-238.

[33] Zhang Shuqing. (1995). Reexamining the affective advantage of peer feedback in the ESL writing class. Journal of Second Language Writing 4(3), 209-222.

Xiaoling Liu was born in Ningxiang, China in 1954. She received her TESOL certificate from City University of New York and master's degree from Hunan University, China in 1987. She is currently a full professor in the College of Foreign languages, Hunan University, Changsha, China. Her research interests include Applied Linguistics, Foreign language Teaching and Learning.

Changping Zhou was born in 1988. She received her master's degree from Hunan University in 2014. She is currently teaching as a lecturer in Shangdong Modern University, Shandong, China. Her research interest is foreign language Teaching and Learning. 